\title{
BIBLIOGRAFÍA ITALIANA DE TEMÁTICA ÁRABE
}

Por

MAGDALENA MARTÍNEZ ALMIRA

Las recientes investigaciones llevadas a cabo por eminentes estudiosos de la cultura islámica, tienen en común la estrecha dependencia del Mar Mediterráneo. La presente Bibliografía, tres libros y una revista, han constituido en el inicio de mi trabajo la introducción al conocimiento de la herencia árabe en la Italia medieval y moderna.

Se trata de libros cuya variada temática abarca aspectos fundamentalmente socio-culturales. Bibliografía que pone de manifiesto el interés suscitado en investigadores y científicos de la Historia y las Letras en Italia. Las concomitancias con la cultura islámica han posibilitado una explicación razonada al comportamiento de las gentes en el mundo mediterráneo.

Al margen de la variada temática, aspecto que trataré más adelante, conviene precisar que nos encontramos ante unos textos de distintos géneros literarios. Desde la obra científica del Profesor Francesco Gabrieli hasta la revista de poesía "Plural», en la que se insertan estudios, bien atribuidos a escritores árabes, bien realizados por investigadores de la talla de Andrea Borruso. Si bien todos ellos responden a un mismo deseo: esclarecer el pasado de los pueblos mediterráneos, en estrecha relación con una herencia musulmana aún vigente en la mayor parte de los mismos.

Siguiendo un criterio cronológico respecto a las publicaciones de los volúmenes presentados, destacaré en primer lugar el libro del Profesor Francesco Gabrieli, llustre arabista italiano, a quien en 1986 le fue concedido el Premio Salinón por su importante labor de investigador; labor que ha dado origen a la obra titulada Pagine Arabo-Siciliane, presentada por Andrea Borruso. El libro del Profesor Gabrieli es un exhaustivo estudio de la trayectoria siciliana durante la Edad Media, bajo la influencia inicial de la cultura islámica. El período referido en su obra abarca desde el S. X hasta los días del propio autor, quien nos conduce a través de la historia de Sicilia de forma ágil y concisa. El Profesor Gabrieli no sólo investiga las fuentes, sino que además pone de 
manifiesto su profundo conocimiento de la influencia islámica medieval. Cita con asiduidad las costumbres y tradiciones de Al-Andalus, sin dejar de mencionar las relaciones socio-económicas con el resto de los países mediterráneos.

En el libro se hace mención a una diferencia esencial con respecto a los dos países citados, Sicilia y España. En efecto, los nueve siglos de permanencia musulmana en España constituyen una seria ventaja al estudiar los dos siglos que permanecieron los árabes en tierras sicilianas. Sin embargo, podemos adivinar la raigambre de la cultura islámica en todos los países de las costas mediterráneas gracias a los vestigios culturales legados por los árabes: poesía (en este sentido el Profesor Gabrieli menciona y exalta la obra de Ibn Hamdís), la agricultura (destacando la riqueza de la isla en el aspecto hídrico y botánico, aspectos que sin lugar a dudas cautivaron a los nuevos pobladores árabes), finalmente en las relaciones socio-políticas con los países colindantes del Mediterráneo.

En estrecha relación con esta obra, se encuentra el volumen editado por L'Academia Selinuntina di Science Lettere Arti Di Mazara del Vallo. El libro dedicado en su práctica totalidad a exaltar la obra del Profesor Francesco Gabrieli, ha contado con la valiosa colaboración de investigadores y científicos italianos de la categoría de: Sabatino Moscati, Roberto Rubinacci, Salvatore Bono, Pier Quirino Tortorici, Adalgisa De Simone y Andrea Borruso. El libro de la Academia Selinuntina pone de relieve la constancia y profundidad de la labor investigadora del Profesor Gabrieli. La lectura de los artículos que componen esta obra muestran la trayectoria científica del maestro, actividad esta última que junto a la docencia son las notas características de Francesco Gabrieli. En última instancia, el autor de Pagine Arabo-Siciliane da forma a una obra histórica basada en el deseo de conocer la dependencia de la Sicilia actual con respecto al entorno y la cultura árabe-medieval.

La obra de las Doctoras Silvia Luciani e Irma Taddia, realizada bajo la dirección de los Profesores Anna Maria Gentili y Salvatore Bono, constituye un vasto compendio de fuentes para el estudio de la historia del África nordoriental. El volumen I publicado por la Università degli studi di Bologna, en 1986, es el resultado de una laboriosa investigación realizada en el Archivo Storico della Congregatione dei Missionai Comboniani, Roma, y de la Biblioteca "Nigrizia" Casa Madre Comboniani di Verona. Fuentes inéditas italianas referentes al área geográfica que comprende Sudán, Etiopia, Somalia, Kenya, Tanzania y Uganda. Desde 1842 se citan una serie de cartas, documentos personales y administrativos, artículos, correspondencia entre misioneros, diapositivas, conferencias y toda suerte de textos que son catalogados de forma exhaustiva, posibilitando el conocimiento del área de acción de los misioneros italianos, en los países africanos anteriormente citados.

Las Doctoras Silvia Luciani e Irma Taddia no han eludido esfuerzos por recabar todo tipo de material, dando lugar a un instrumento de trabajo de suma importancia. El volúmen I presagia la aparición de sucesivos tomos, siguien- 
do la misma línea científica, como ponen de manifiesto los Profesores Anna Maria Gentili y Salvatore Bono en la Introducción. Tarea que fue emprendida por un grupo de estudiosos italianos que se propusieron llegar a conocer con precisión las Fuentes Italianas para el estudio de la Historia de África. Confiamos que sucesivos volúmenes permitan sacar a la luz una obra de conjunto, cuya riqueza posibilite la simplificación en el conocimiento de las culturas africanas.

La Revista de poesía y literatura italiana y extranjera, publicada en el mes de junio de 1987, bajo el título Plural, es la última obra a presentar. Se trata de un compendio de poesía con temática sensualista y mundana, así como una serie de artículos entre los que cabe mencionar especialmente el firmado por Andrea Borruso: La vida sexual en la literatura árabe del siglo VI al XVI. El artículo nos permite afirmar la evidente preocupación por parte de los intelectuales y hombres de letras de nuestro siglo por recuperar la sensibilidad y estética de la literatura árabe. Poesía dotada de una enorme carga sensual, cuya esencia perdura en el alma de los poetas mediterráneos, aferrándose a la intuición legada por aquellos cantores de las maravillas del mundo de los sentidos. El artículo nos introduce además en el complejo mundo de la permisividad sexual reseñada en el Corán. Aspectos jurídicos y religiosos son expuestos y tratados con carácter científico, con el fin de dar a conocer al lector la complejidad de la cultura islámica. 